\title{
The effectiveness of intervention with board games: a systematic review
}

\author{
Shota Noda ${ }^{1 *} \mathbb{D}$, Kentaro Shirotsuki ${ }^{2}$ and Mutsuhiro Nakao ${ }^{3}$
}

\begin{abstract}
To examine the effectiveness of board games and programs that use board games, the present study conducted a systematic review using the PsycINFO and PubMed databases with the keywords "board game" AND "trial;" in total, 71 studies were identified. Of these 71 studies, 27 satisfied the inclusion criteria in terms of program content, intervention style, and pre-post comparisons and were subsequently reviewed. These 27 studies were divided into the following three categories regarding the effects of board games and programs that use board games: educational knowledge (11 articles), cognitive functions (11 articles), and other conditions (five articles). The effect sizes between pre- and post-tests or pre-tests and follow-up tests were 0.12-1.81 for educational knowledge, 0.042.60 and $-1.14--0.02$ for cognitive functions, $0.06-0.65$ for physical activity, and $-0.87--0.61$ for symptoms of attention-deficit hyperactivity disorder (ADHD). The present findings showed that, as a tool, board games can be expected to improve the understanding of knowledge, enhance interpersonal interactions among participants, and increase the motivation of participants. However, because the number of published studies in this area remains limited, the possibility of using board games as treatment for clinical symptoms requires further discussion.
\end{abstract}

Keywords: Board game, Systematic review, Education, Cognitive function

\section{Background}

A board game is a generic term for a game played by placing, moving or removing pieces on a board and that utilizes a game format in which pieces are moved in particular ways on a board marked with a pattern. Examples of board games include chess, Go, and Shogi. Research involving chess, which is played by two players on a board with 64 black and white squares and 16 pieces for each player [1], has contributed to the theoretical development of cognitive psychology [2]. For example, Burgoyne et al. [3] conducted a meta-analysis and demonstrated that chess skills are significantly and positively correlated with four broad cognitive abilities: fluid reasoning, comprehension-knowledge, short-term memory, and processing speed. Similarly, a metaanalysis by Sala and Gobet [4] found that chess instruction moderately improves the cognitive skills of children.

In contrast, Go is ancient board game that consists of simple elements (a line and circle, black and white

\footnotetext{
* Correspondence: norashouta@outlook.jp

${ }^{1}$ Graduate School of Human and Social Sciences, Musashino University, 3-3-3 Ariake, Koutouku, Tokyo 135-8181, Japan

Full list of author information is available at the end of the article
}

colors, and stone and wood materials) combined with simple rules that generate subtleties that have enthralled players for millennia [5]. Go is a famous board game in Asian countries and has been used as a tool for increasing or maintaining brain activity for more than 5000 years [6]. It is currently gaining popularity in the United States and Europe [6], and Kim et al. [7] has suggested that playing Go might be effective for children with attention-deficit hyperactivity disorder (ADHD) due to its activation of hypo-aroused prefrontal cortical function and the enhancement of executive function. Lin et al. [8] conducted an intervention study using GO in patients with Alzheimer's disease and showed that playing Go can also improve the clinical symptoms associated with depression, anxiety, and Alzheimer's Disease. Similar to chess and Go, Shogi is a board game for two players that is also referred to as Japanese chess. Wan et al. [9] conducted an experiment with undergraduate students and found that Shogi training is related to activation in the head of the caudate nucleus. Taken together, the abovementioned findings suggest that chess, Go, and Shogi are effective ways to achieve various outcomes. 
There are many board games other than chess, Go, and Shogi. For example, educational board games, such as Kalèdo, have been used to improve nutrition knowledge and promote a healthy lifestyle for children [10]. Zeedyk et al. [11] investigated the effectiveness of a board game for increasing knowledge about road safety and danger and found that the interventions were significantly effective in increasing children's knowledge. Although the impacts of various board games have been previously examined, their effects have yet to be comprehensively reviewed. As a result, the functions and effects of board games as a whole remain unclear. Thus, the present review systematically examined the effectiveness of board games and programs that use board games.

\section{Methods}

For the present review, a literature search based on the Preferred Reporting Items for Systematic Reviews and Meta-Analyses [12] using the PsycINFO and PubMed databases was conducted to collect findings on the effectiveness of board games and programs using board games. The keywords for the literature search were "board game" AND "trial," and the date selected was September 13th, 2018. The search identified nine studies from PsycINFO and 32 studies from PubMed. The first author of this review performed a manual search that identified six additional studies, and 24 additional studies were extracted from Sala \& Gobet [4], which conducted a meta-analysis about the benefits of chess. Duplicate studies were deleted and, ultimately, a list of references consisting of 66 articles was prepared.
The inclusion criteria for the present study were as follows: (a) studied the effects of board games and programs using board games on psychological and educational outcomes, (b) included pre-post comparative tests, (c) used an interventional or experimental rather than a review approach, (d) had full text availability, (e) was written in English, and (f) was peer reviewed. A screening to remove articles that were judged not to satisfy any of the criteria from (a) to (f) was conducted, and 29 articles were extracted. Additionally, one study was excluded because it did not use a traditional board game (it used a Wii Fit balance board), and one study was excluded because the content details of the board game were unclear. Ultimately, 27 articles were selected for the present study; the literature search process is presented in Fig. 1.

Furthermore, in the studies where the means and standard deviations of the intervention group are described, Cohen's d was calculated to assess effect sizes between pre- and post-tests or between pre-tests and follow-up tests with the following formula based on Cohen [13].

$$
\begin{aligned}
& d=\frac{M_{2}-M_{1}}{S D_{\text {pooled }}} \\
& S D_{\text {pooled }}=\sqrt{\left(\left(n_{2}-1\right) S D_{2}^{2}+\left(n_{1}-1\right) S D_{1}^{2} / n_{n_{2}+n_{1}-2}\right)}
\end{aligned}
$$

Note: $M_{1}$ and $M_{2}$ are the mean of the intervention group at the pre-test session and the post-test session or

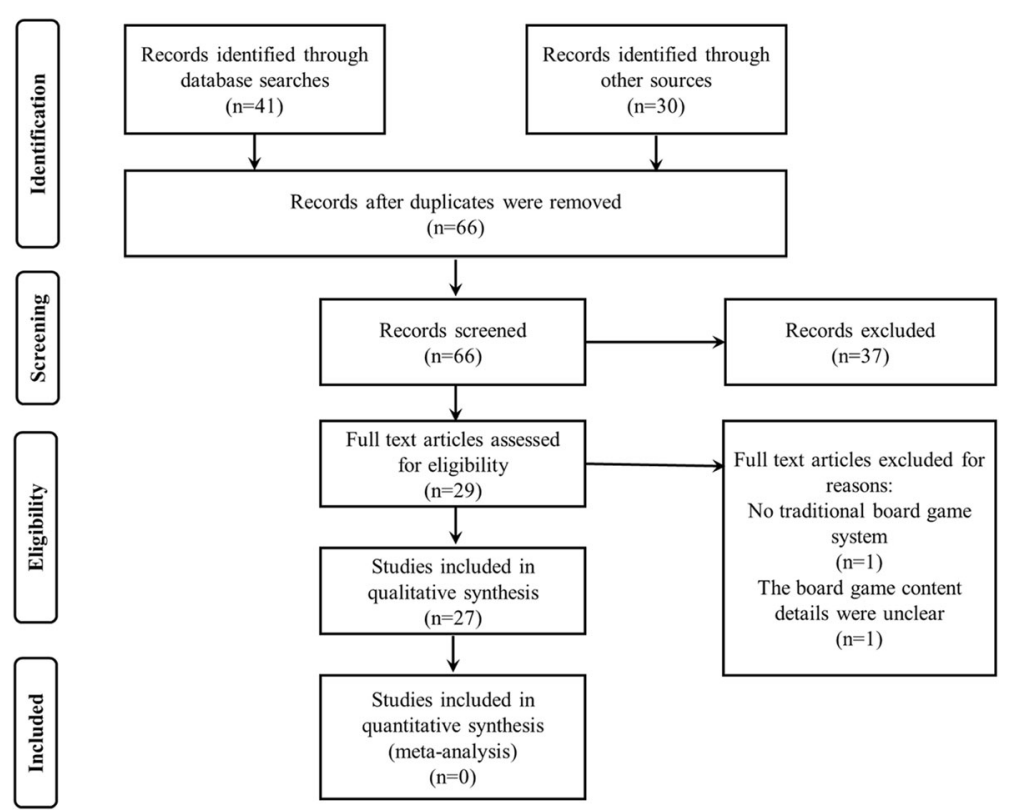

Fig. 1 PRISMA flow chart of the study selection process 
follow-up test session, respectively. SDpooled is the pooled standard deviation $\left(S D_{1}\right.$ is the standard deviation of the intervention group at the pre-test session and $S D_{2}$ is the standard deviation at the post-test session or follow-up test session). $n_{1}$ is the number of samples at the pre-test session. $n_{2}$ is the number of samples at the post-test session or follow-up test session.

In the studies where the means and standard deviations are described in the intervention group and the other groups, Cohen's d was also calculated to assess effect sizes compared to the other groups (control groups) with the following formula based on Sala et al. [14].

$$
\begin{aligned}
& d=\frac{M_{g i}-M_{g c}}{S D_{\text {pooled-pre }}} \\
& S D_{\text {pooled-pre }}=\sqrt{\left(\left(n_{i}-1\right) S D_{\text {pre. }}{ }^{2}+\left(n_{c}-1\right) S D_{\text {pre. }}{ }^{2} / n_{i}+n_{c}-2\right)}
\end{aligned}
$$

Note: $M g i$ and $M g c$ are the mean gain of the intervention group and the control group (other group) at the post-test session or at the follow-up test session, respectively, and SDpooled-pre is the pooled standard deviation of the two pre-test standard deviations. SDpre. $i$ is the standard deviation of the intervention group at the pretest session, and SDpre.c is the standard deviation of the control group at the pre-test session. $n i$ is the number of samples in the intervention group who received the pretest session and post-test session or the pre-test session and follow-up test session. $n c$ is the number of samples in the control group who received the pre-test session and post-test session or the pre- test session and followup test session.

According to Cohen [13], Cohen's d of approximately 0.20 is small, 0.50 medium, and 0.80 large.

\section{Results and discussion}

\section{The effect of interventions with board games}

In the present review, the selected studies were divided into the following three categories regarding the effects of board games and programs that use board games: educational knowledge (11 articles), cognitive functions (11 articles), and other conditions (five articles).

An overview of the findings about the effects of board games and programs that use board games related to educational knowledge is shown in Table $1[10,11$, 15-23]. Board games in this category were used for the purpose of improving educational knowledge, and the effect sizes (Cohen's d) between pre- and posttests or between pre-tests and follow-up tests ranged from 0.12 to 1.81 and between the mean gain of the main intervention group and the other groups ranged from 0.81 to 0.93 and -1.84 to -1.65 .
An overview of the findings about the effects of board games and programs that use board games on cognitive functions is shown in Table 2 [6, 24-33]. This category included board games such as Go, Ska, and chess, and the effect sizes (Cohen's d) between pre- and post-tests of cognitive function ranged from 0.04 to 2.60 and -1.14 to -0.02 . The effect size of the exacerbation was calculated in only the chess group of Sala et al. [27]. The effect sizes (Cohen's d) between the mean gain of the main intervention group and the other groups ranged from 0.06 to 2.36 and -1.38 to -0.22 .

An overview of the findings about the effects of board games and programs that use board games on other conditions is shown in Table $3[7,8,34-36]$. This category addressed the impacts of board games on physical activity, anxiety, ADHD symptoms, and the severity of Alzheimer's Disease. The effect sizes (Cohen's d) between pre- and post-tests or between pre-tests and follow-up tests ranged from 0.06 to 0.65 for physical activity and from -0.87 to -0.61 for ADHD symptoms.

\section{Board games and educational knowledge}

Eleven studies that used board games to increase educational knowledge were selected for this review. The present findings showed that board games influence educational knowledge and concomitant outcomes, with the effect sizes for educational knowledge ranging from very small to large.

Board games can be used as a tool to encourage learning. In previous studies, specialized board games aimed at improving knowledge in the field of education were targeted and subsequently developed and investigated. For example, Wanyama et al. [16] conducted a study of the Make a Positive Start Today game, which is a board game aimed at improving knowledge about human immunodeficiency virus (HIV) and sexually transmitted infections (STIs). Similarly, Kalèdo is an educational board game used to increase nutrition knowledge $[10,19,21]$. It has been shown that these board games contribute to increasing knowledge related to each particular field.

Board games are also efficacious for goals other than increasing knowledge. According to Charlier and De Fraine [22], board games can be an enjoyable and motivational method for learning content and enhancing group interactions, competition, and fun. Martins et al. [18] reported that board games teach educational content in a playful and enjoyable way and involve interactions with family and friends; thus, they favor knowledge acquisition by enabling exchanges of experiences and learning. Furthermore, Wanyama et al. [16] showed that, as a method of health education, board games increase the acquisition of knowledge as well as result in more positive experiences than do health talks among both participants and facilitators. Amaro et al. [10] found that 


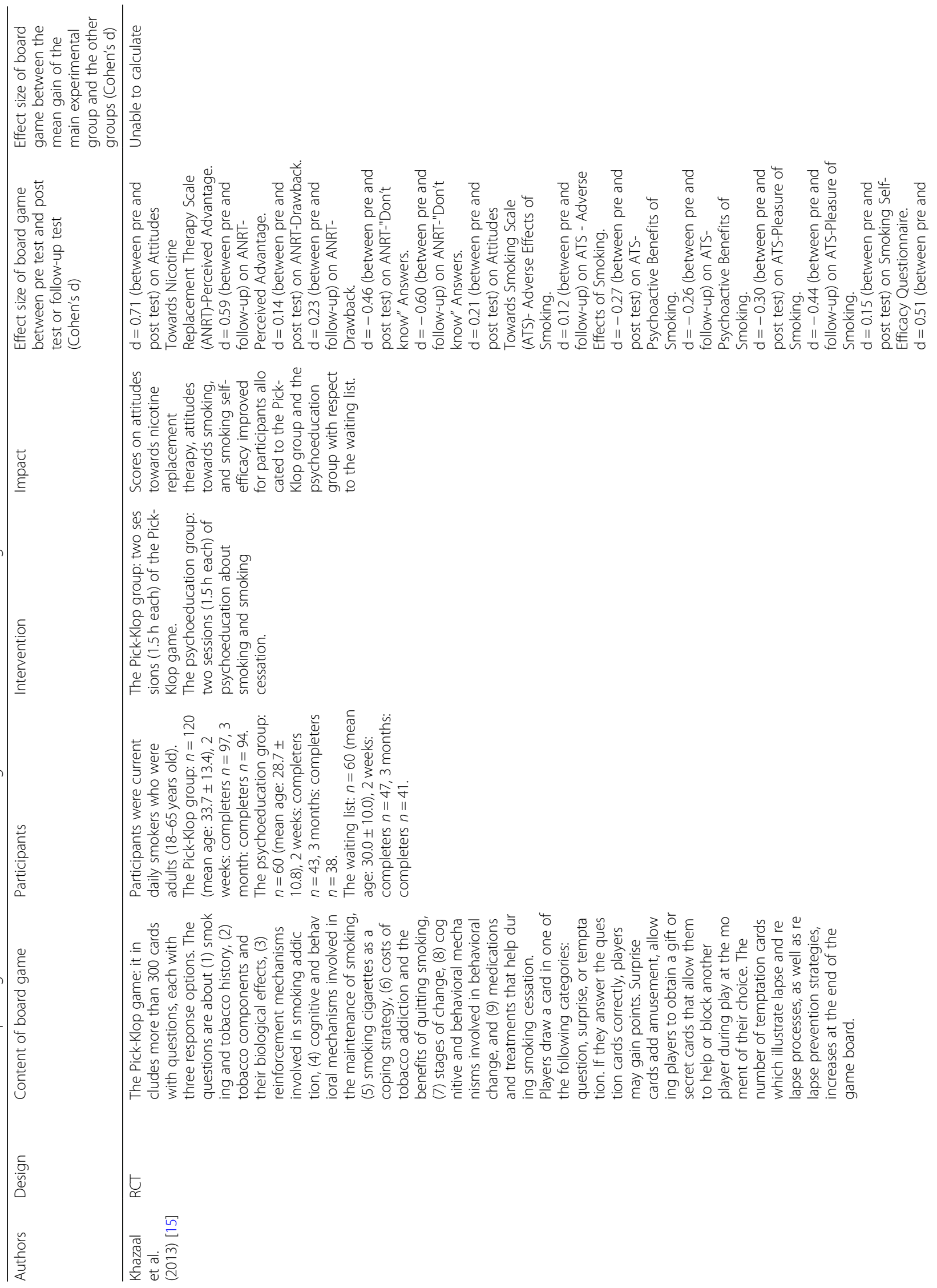




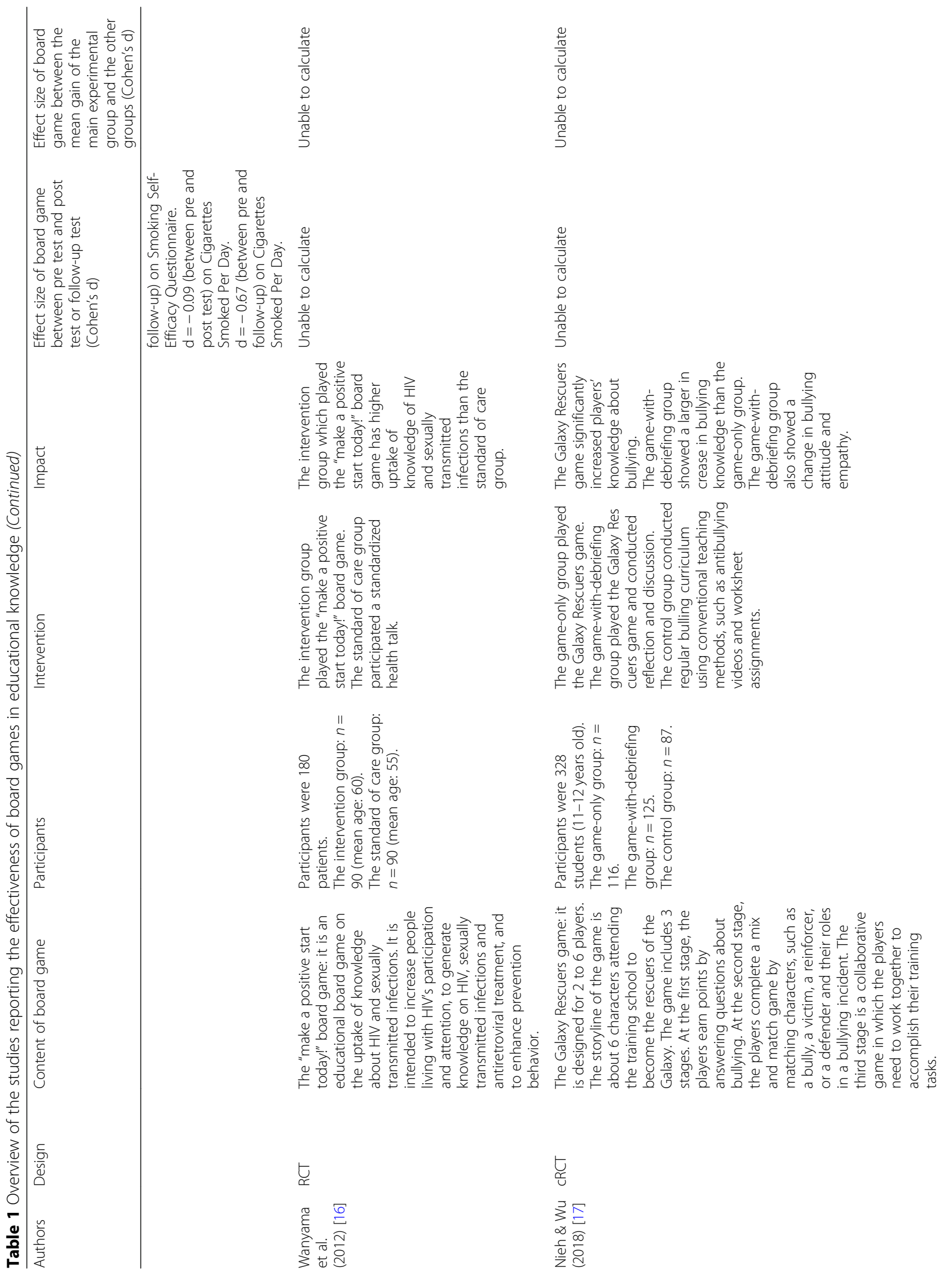




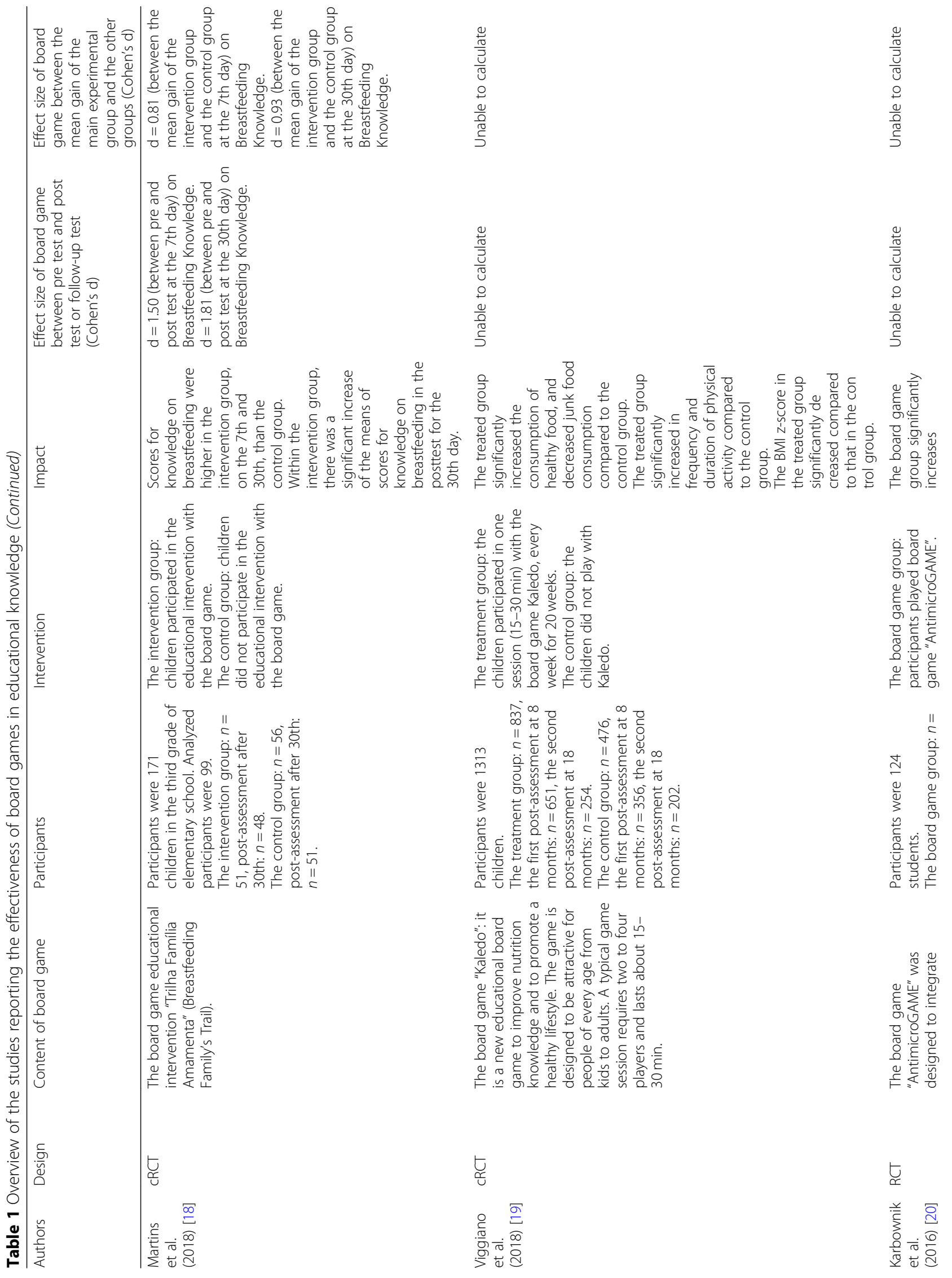




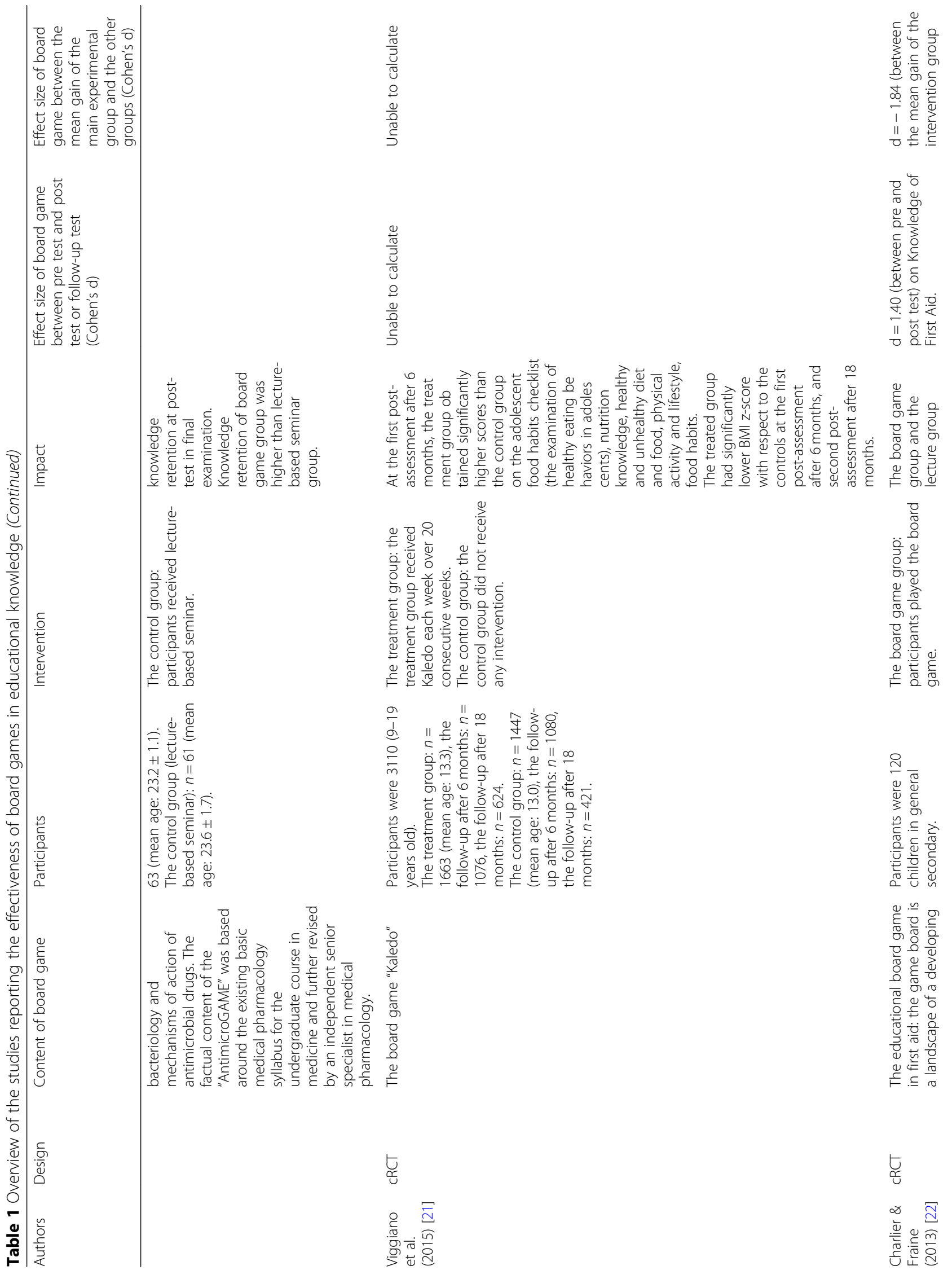




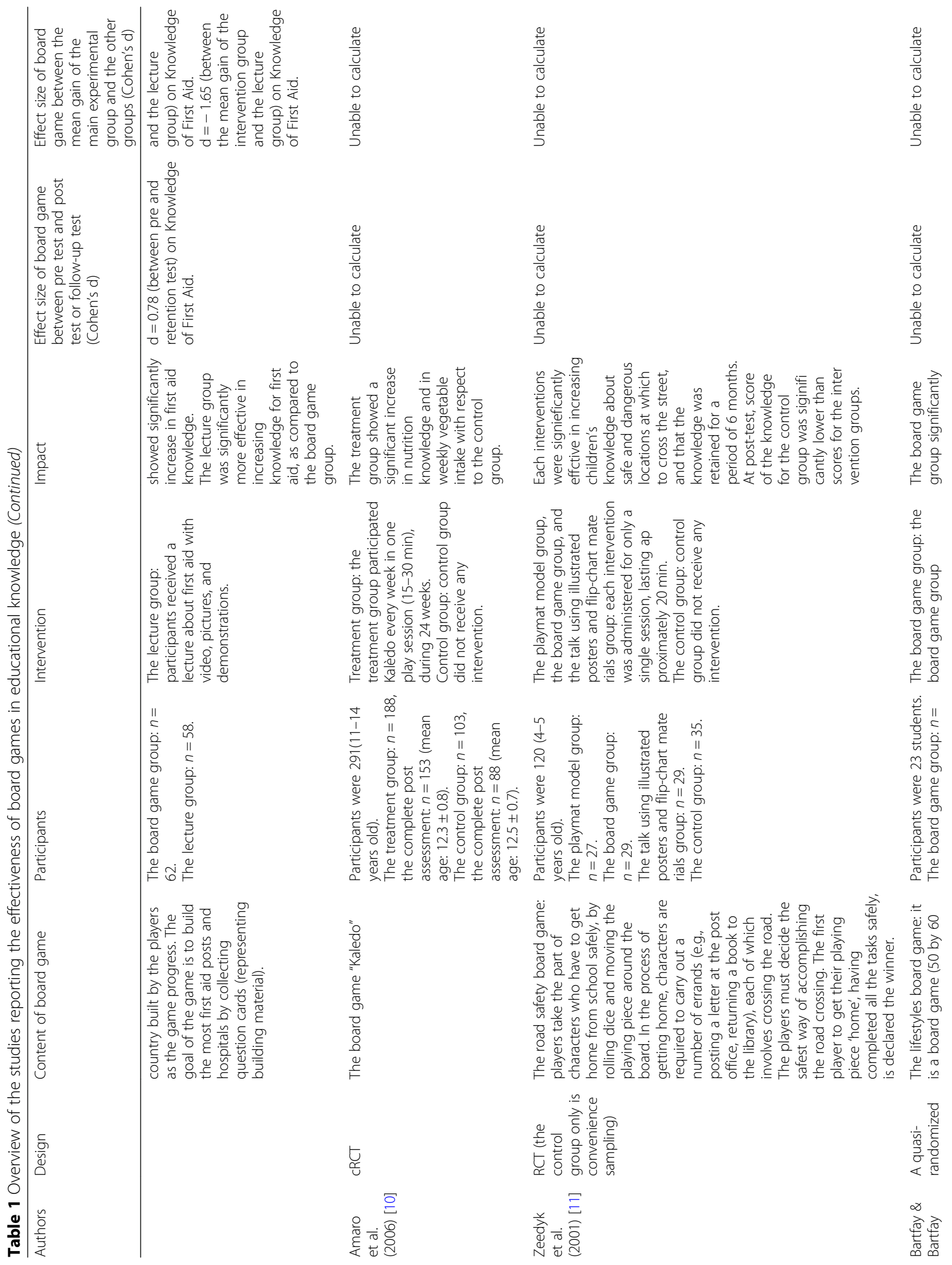




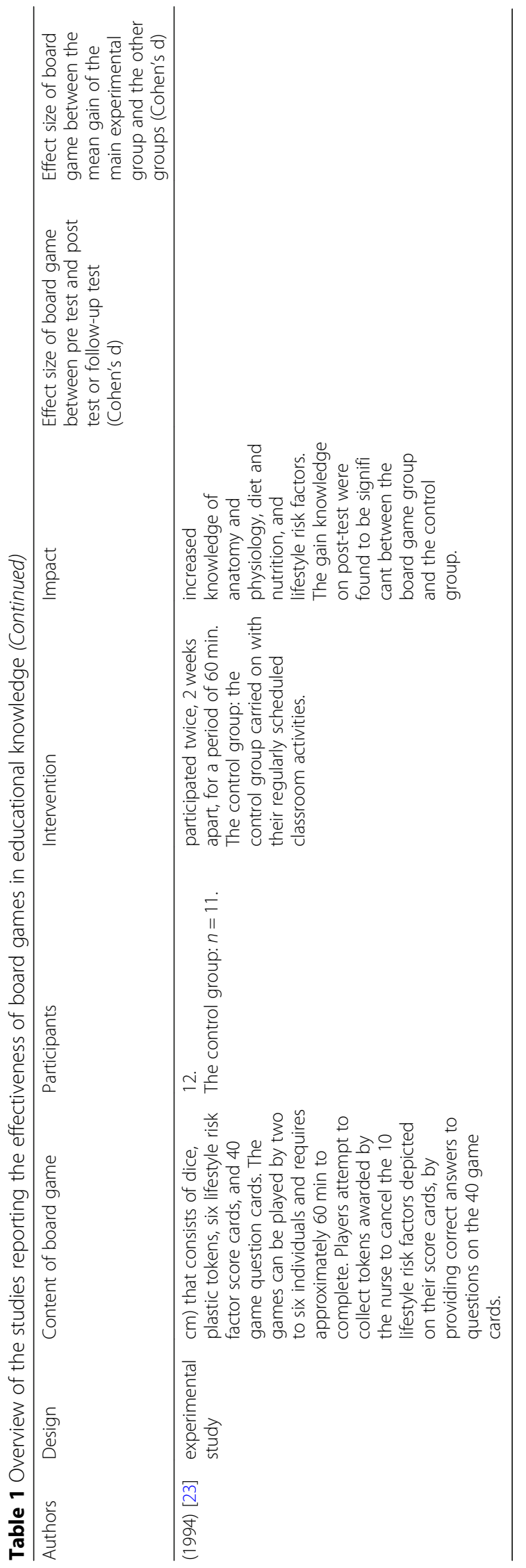




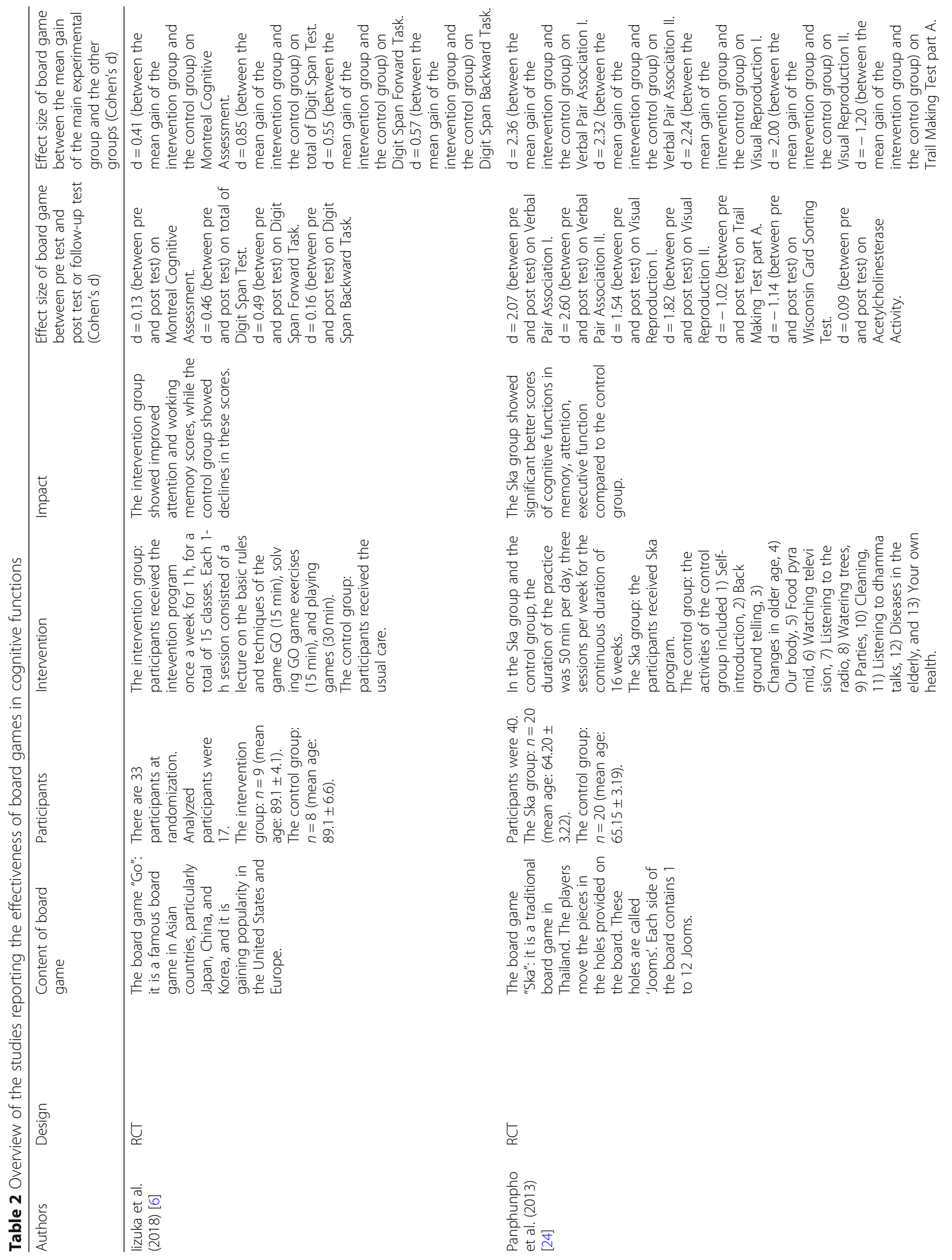




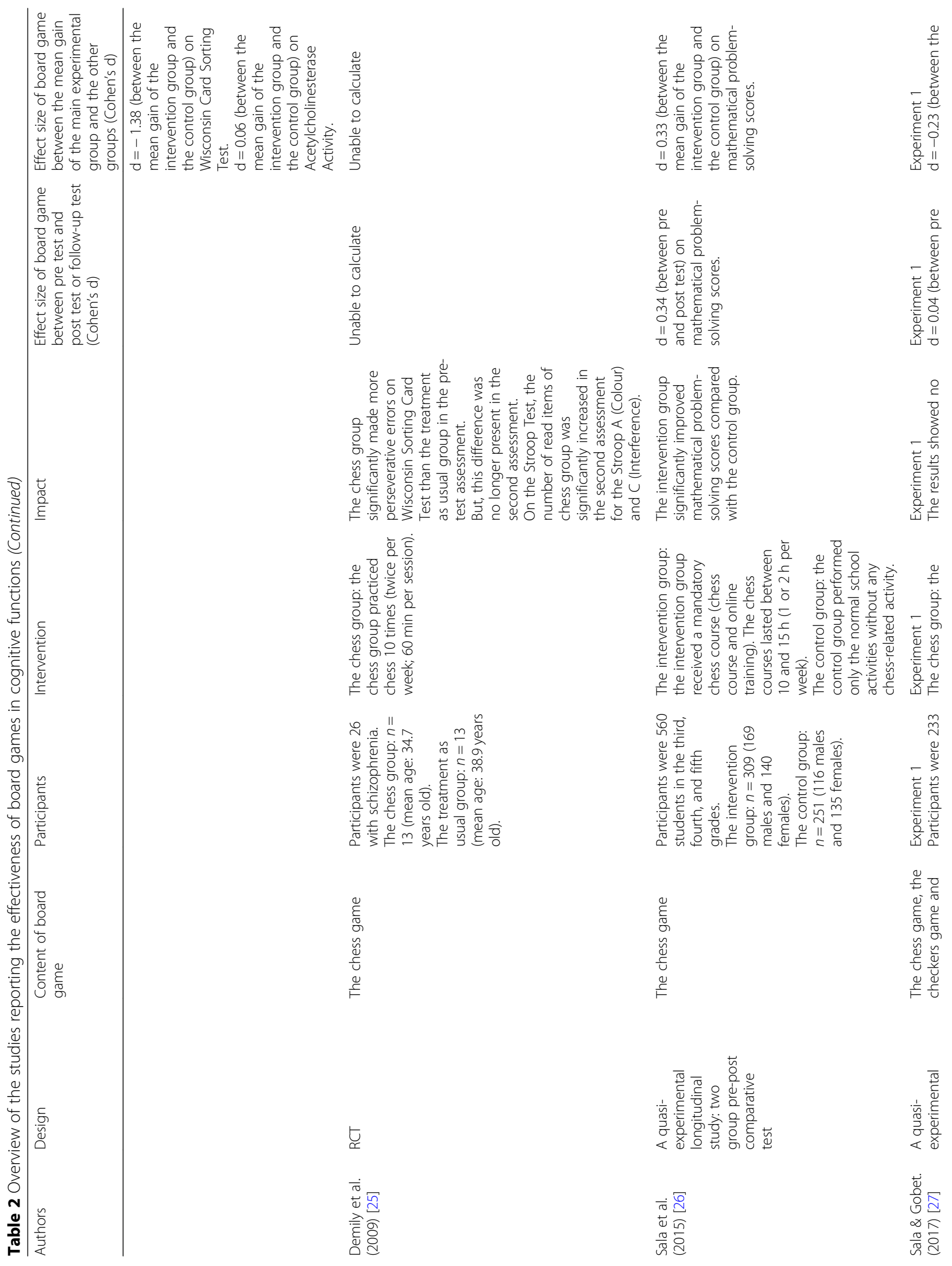









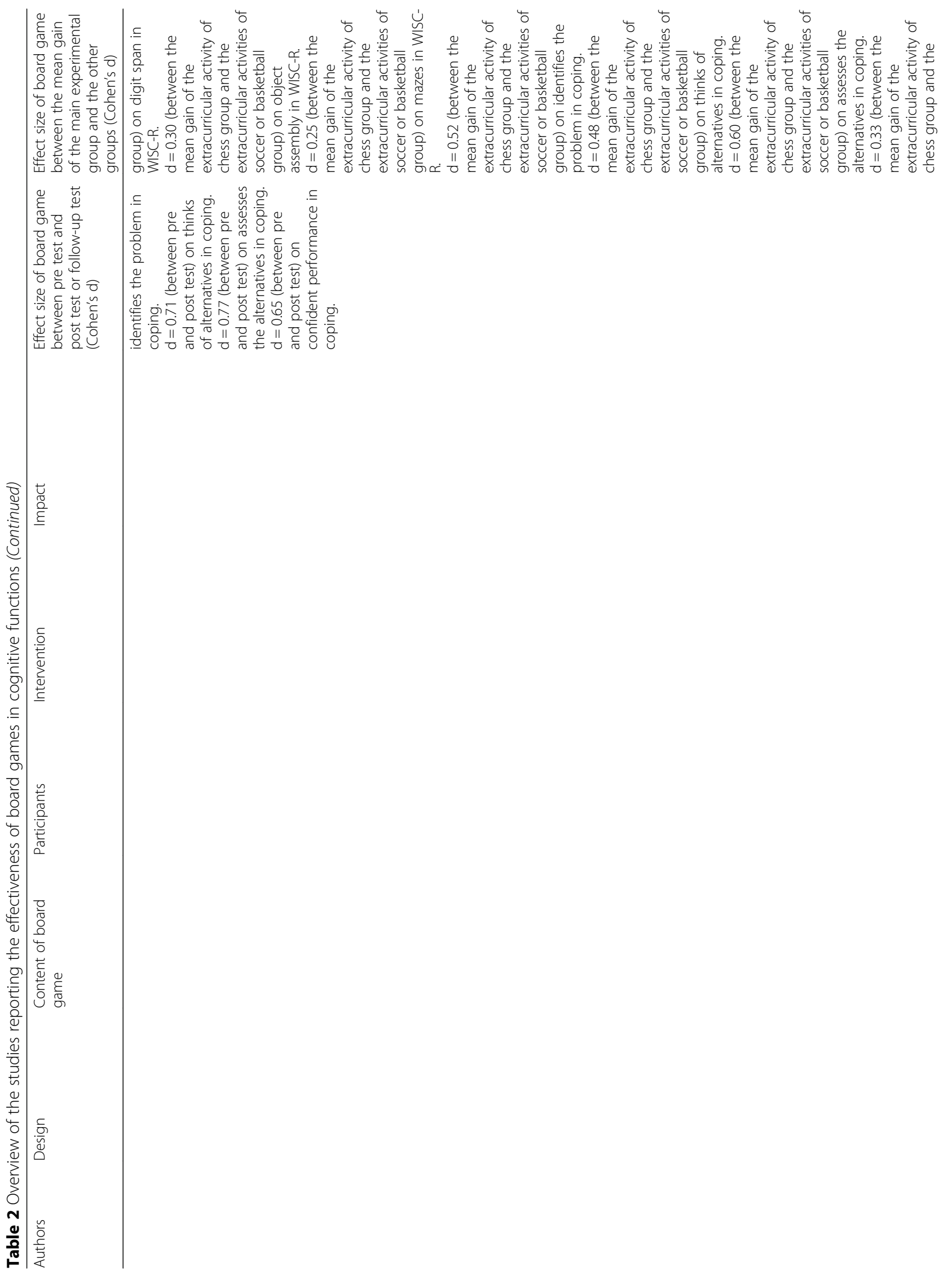




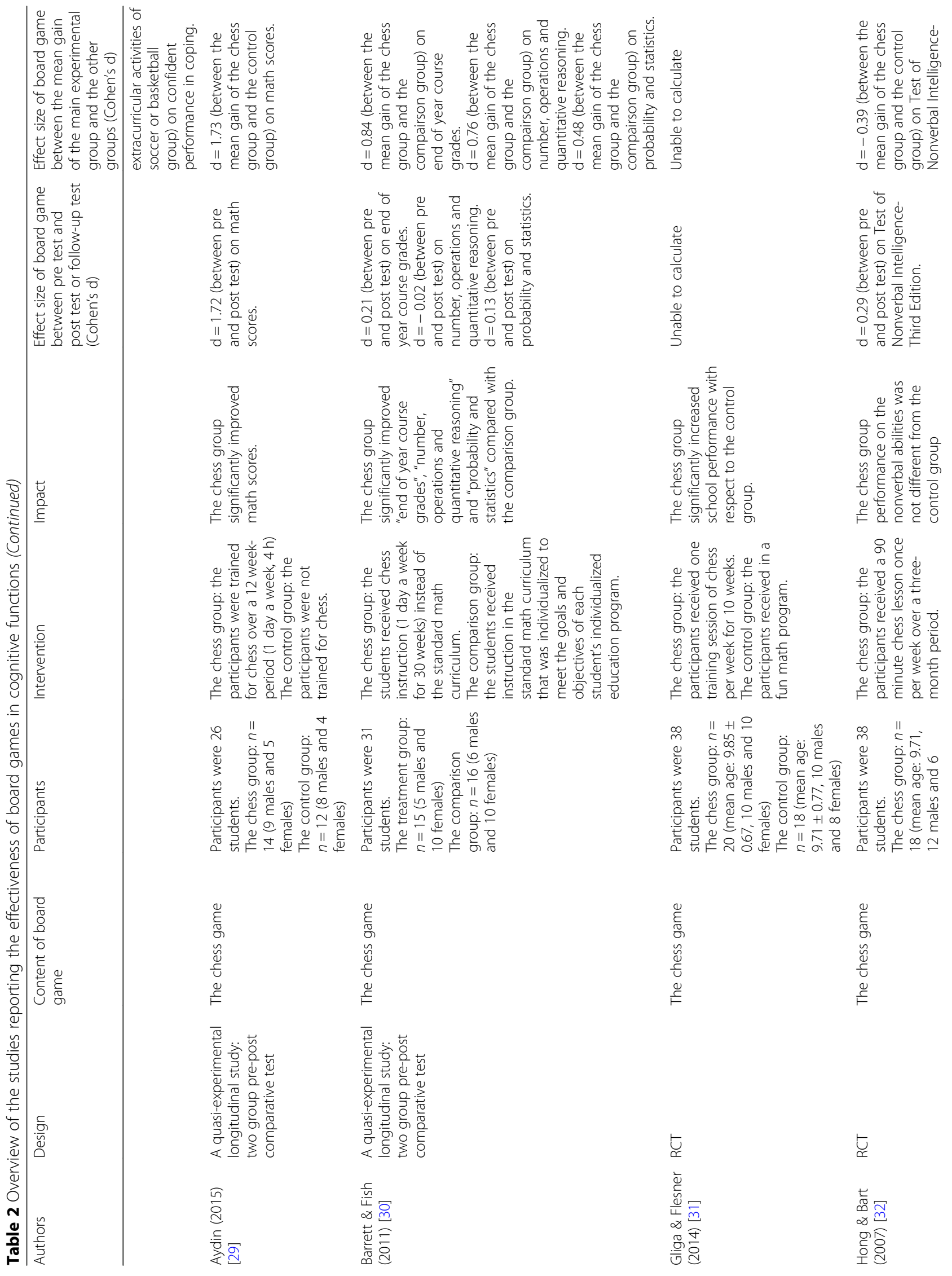




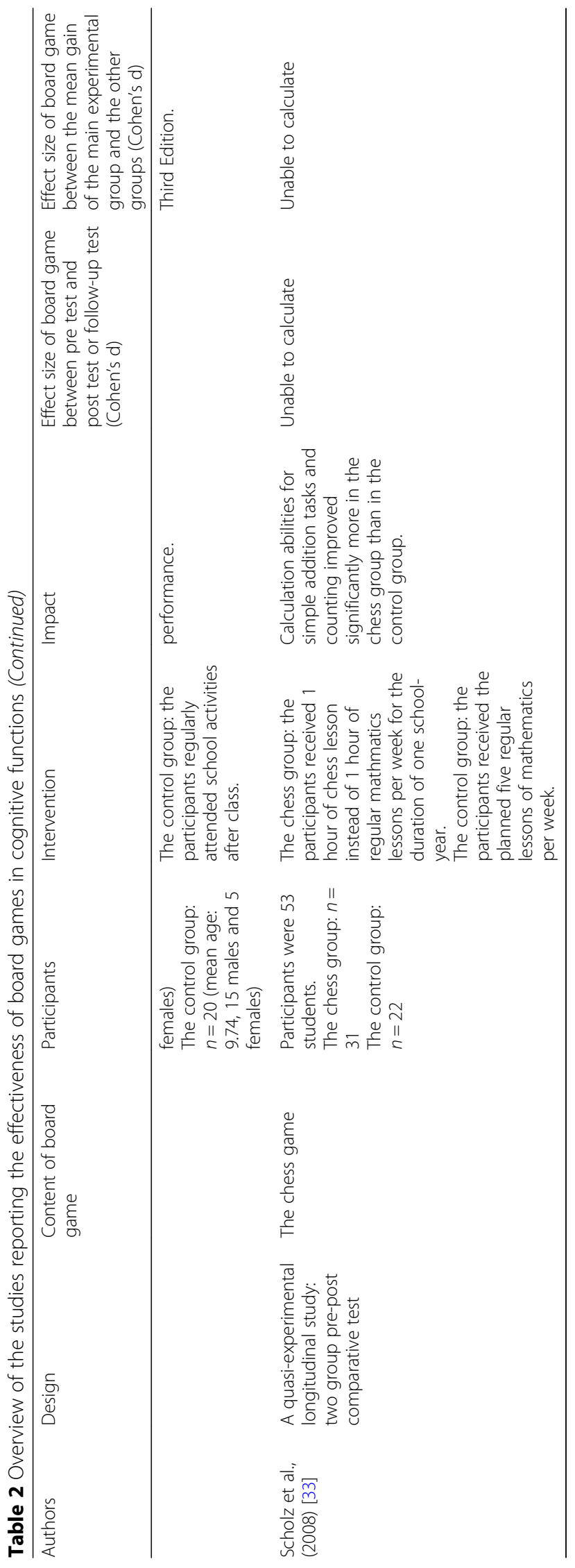




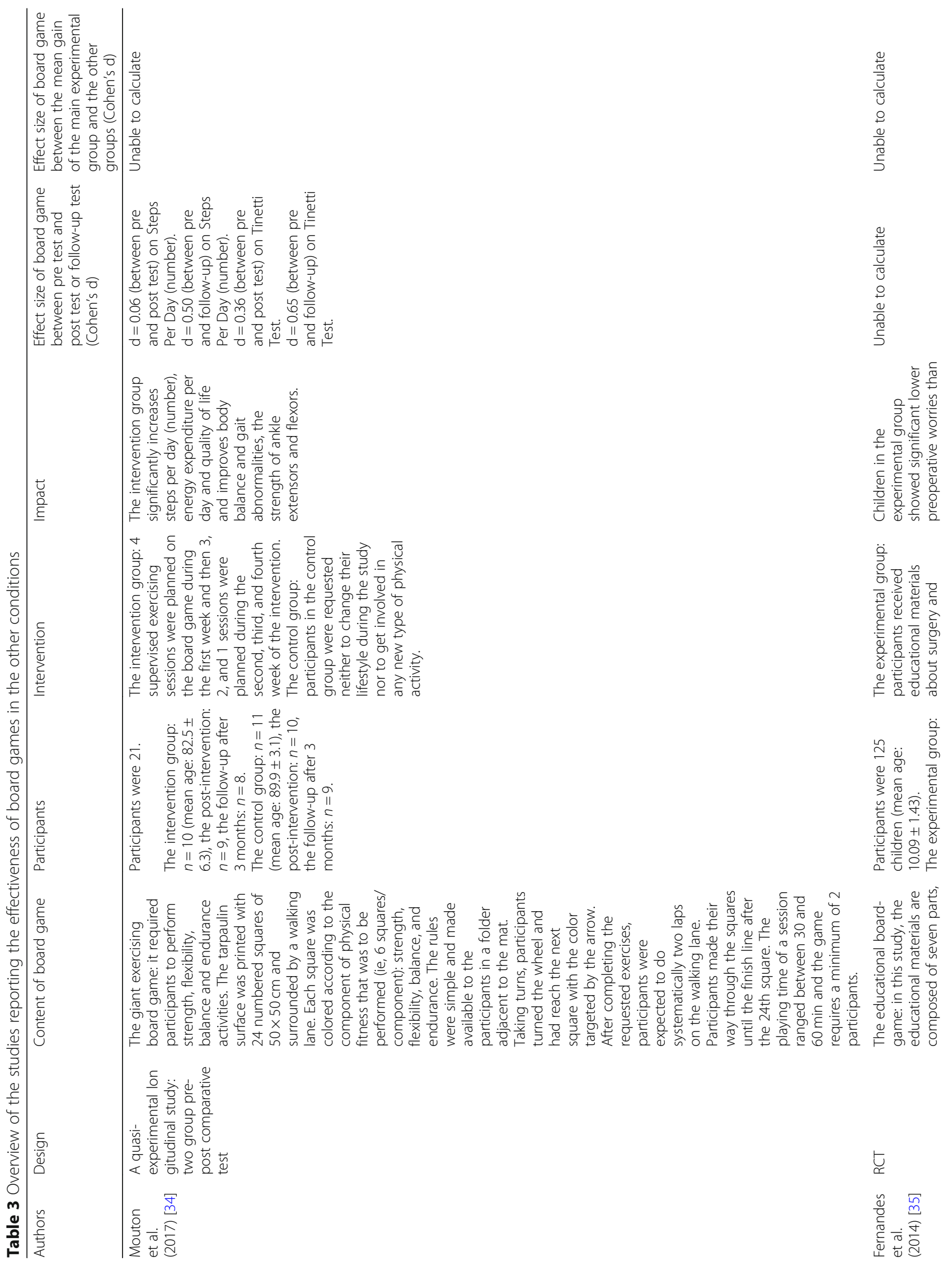




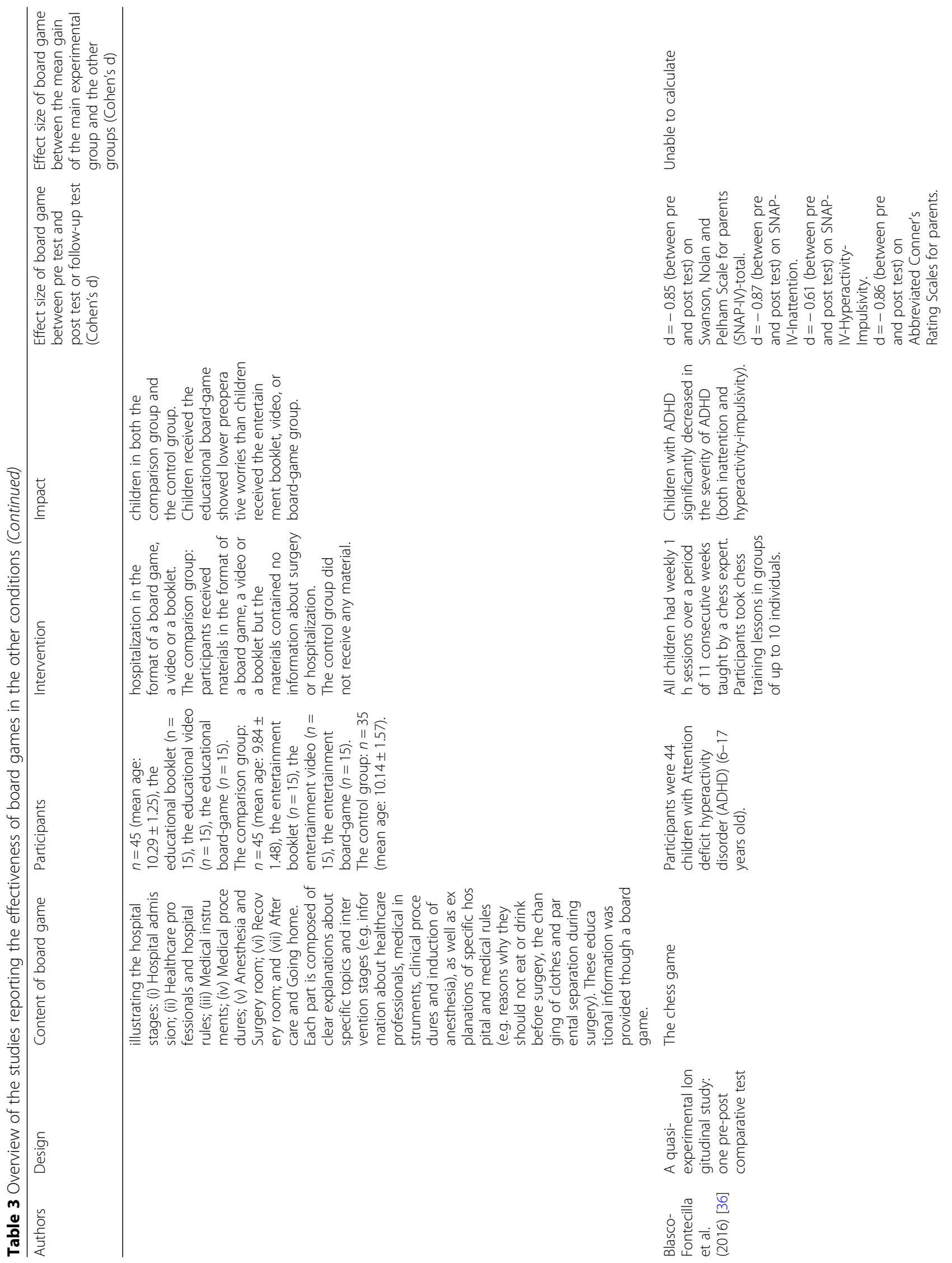




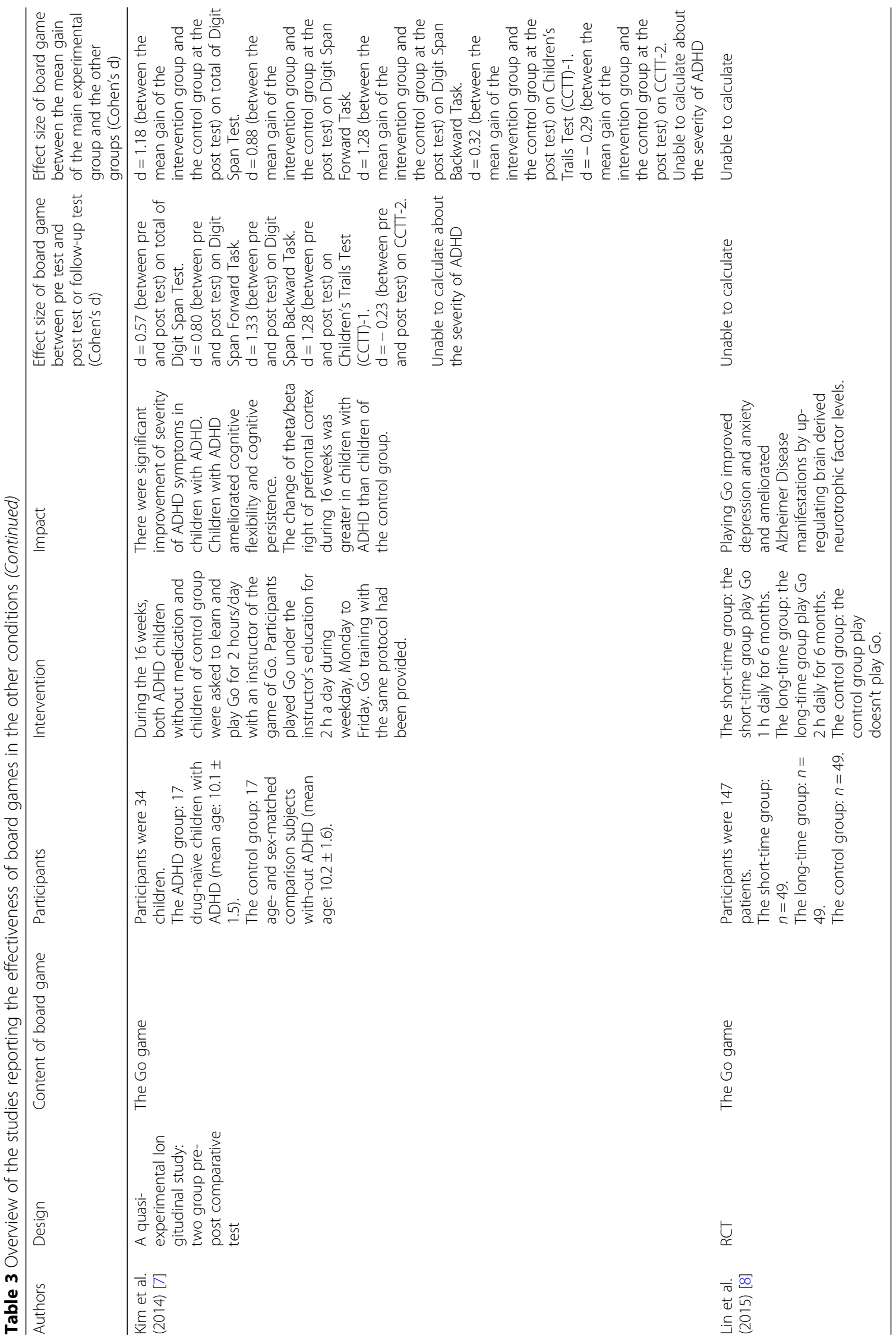


class teachers noted improvements in student interest and appreciation of the board game. Taken together, these findings suggest that board games may improve the motivation of participants. Furthermore, Karbownik et al. [20] showed that a board game was warmly welcomed by students; in their opinion, it facilitated clinical thinking and peer communication. Therefore, board games may also have a positive influence on interpersonal interactions among participants.

Based on the above findings, board games can be used as a tool to encourage learning as well as to enhance motivation and interpersonal interactions. In clinical treatment, it is important to increase motivation because low motivation to cooperate with a particular intervention may lead to a patient dropping out of treatment or to interference with the therapeutic effects. Based on the above findings, the use of board games may help increase the benefit of treatment for less motivated patients.

\section{Board games and cognitive functions}

In the present review, 11 of the assessed studies investigated the effects of board games and programs that use board games on cognitive functions. These studies used Go, chess, and Ska, which are not educational games but abstract strategy games. Studies investigating the use of Go found that older adults experiencing cognitive decline and/or living in nursing homes showed improvements in attention and working memory after regularly playing the game [6]. Studies assessing the use of Ska found that the game appeared to enhance the cognitive functioning of older adults in terms of memory, attention, and executive function [24]. Studies evaluating chess showed that training with the game improved the planning ability of patients with schizophrenia and the mathematical ability of children [25, 26]. But, Sala \& Gobet [27] indicated that interventions that use chess are not significantly different from interventions that use checkers and regular school activities that address the mathematical and metacognitive ability of children.

The effect sizes for cognitive functions ranged from very small to large, but the effect size of exacerbation on metacognitive ability was shown in the chess training of Sala \& Gobet [27]. The number of studies included in this category was relatively limited. Further investigations will be necessary to clarify the more detailed effects of board games on cognitive function. Articles about Shogi were not selected for this category in the present review. Because Shogi was also included with the abstract strategy games, this may influence cognitive functions. In the future, it will be necessary to use intervention studies to examine the effects of additional types of board games, including Shogi, on cognitive function.

\section{Board games and other conditions}

The "other studies" category in the present review included five studies that examined the effects of board games on physical activity, physical and psychological outcomes, ADHD symptoms, and the severity of Alzheimer's Disease. Mouton et al. [34] showed that a giant board game intervention for nursing home residents led to significant increases in ambulatory physical activity, daily energy output, quality of life, balance and gait, and ankle strength. The effect sizes in the present review of studies related to physical activity ranged from very small to medium. Fernandes et al. [35] reported that board games used as educational preoperative materials decreased the preoperative anxiety of children. Additionally, the use of board games contributed to improvements in the ADHD symptoms of children [7, 35]. The effect sizes for ADHD symptoms in the present review ranged from medium to large. Lin et al. [8] showed that playing Go improved the symptoms of depression and anxiety and ameliorated the manifestations of Alzheimer's Disease. Although a study by Barzegar and Barzegar [37] was not selected for the present review because it was a case report, these authors found that playing chess prevented panic attacks and contributed to the amelioration of this condition. Taken together, these findings indicate that board games might be an effective complementary intervention for the treatment of the clinical symptoms of ADHD and Alzheimer's Disease.

In terms of Alzheimer's disease, board games may also play a role in the prevention of the onset of this disorder. According to an epidemiological survey in Japan [38], the prevalence rates of dementia in 1980, 1990, and 2000 were $4.4,4.5$, and 5.9, respectively, for all types of dementia and 1.9, 2.5, and 3.6, respectively for Alzheimer's Disease. In Japan, the number of patients with Alzheimer's disease has increased, and the prevention of this disorder is a problem that must be addressed. Because playing board games ameliorates the manifestations of Alzheimer's disease [8], these types of games may contribute to the prevention of this disorder. However, the number of studies in the present review that investigated the effects of board games on clinical symptoms was quite small, and further research will be required.

\section{Possible clinical applications of board games}

It is also important to note that board games can be played without the use of language. Language-based therapies may not be appropriate for people with underdeveloped linguistic functions, such as children and patients with speech disorders. However, board games may be a viable treatment option for these populations. In the present review, the subjects in 18 of the assessed studies included children, which is a group that is still developing linguistic functions and is more likely to have poor knowledge about diseases. The present review also 
revealed that board games and programs that use board games are effective for achieving various outcomes for children, including increasing educational knowledge, enhancing cognitive functions, and decreasing anxiety and the severity of ADHD. Furthermore, board games can be an enjoyable and motivational tool for children [22]. Based on these findings, it is possible that board games can be a useful intervention for children in particular because such games can be expected to result in the maintenance and promotion of health and the prevention of disease.

\section{Limitations and future directions}

Several limitations of the present study must be considered. First, the number of studies assessed in the present review was rather limited. Therefore, further investigations of the effects of board games will be necessary. Second, many of the papers selected for the present review examined the effectiveness of board games by comparing prepost intervention for a single group or by comparing with a control group without intervention. These research designs do not control for the possibility of placebo effects. Intervention studies must include an active control group to control for possible placebo effects [39], thus it will be necessary to compare the effect of board game groups and active control groups in future research. Third, in the articles selected for the present review, some studies were conducted with relatively small sample sizes. In cases in which the sample size is small, there is the possibility of increased sampling error. In order to reduce sampling error, it is necessary to do a power analysis to set an appropriate sample size in intervention studies. In addition, it is desirable that multiple assessment indicators be used to examine the effects of board games in various perspectives and to reduce measurement errors.

\section{Conclusions}

The present systematic review showed that board games and programs that use board games have positive effects on various outcomes, including educational knowledge, cognitive functions, physical activity, anxiety, ADHD symptoms, and the severity of Alzheimer's Disease. Additionally, board games were shown to contribute to improving these variables, enhancing the interpersonal interactions and motivation of participants, and promoting learning. Taken together, these findings suggest that board games would be an effective complementary therapy that would contribute to the improvement of many clinical symptoms.

\section{Abbreviations}

ADHD: Attention-deficit hyperactivity disorder; CRCT: cluster randomized controlled trial; HIV: Human immunodeficiency virus; RCT: Randomized controlled trial; STIs: Sexually transmitted infections

\section{Acknowledgements}

The authors appreciate the support of the members of the Japan Shog Association and the officials in Kakogawa City for conceptualizing health promotion models using board games, such as Shogi and other traditional games.

Research involving animals

Not applicable.

Note

This paper was proofread in English by Textcheck (reference number: 19022617).

Authors' contributions

SN designed the study and conducted the literature searches. SN wrote the first draft of the manuscript. KS and MN revised the draft of the manuscript. All authors approved the final version of the manuscript.

Funding

Not applicable.

Availability of data and materials

Not applicable.

Ethics approval and consent to participate

Not applicable.

Consent for publication

Not applicable.

Competing interests

The authors declare that they have no competing interests.

\section{Author details}

${ }^{1}$ Graduate School of Human and Social Sciences, Musashino University, 3-3-3 Ariake, Koutouku, Tokyo 135-8181, Japan. ${ }^{2}$ Faculty of Human Sciences, Musashino University, Tokyo, Japan. ${ }^{3}$ Department of Psychosomatic Medicine, School of Medicine, International University of Health and Welfare, Chiba, Japan.

Received: 23 March 2019 Accepted: 25 September 2019

Published online: 21 October 2019

References

1. El Daou BMN, El-Shamieh SI. The effect of playing chess on the concentration of ADHD students in the 2 nd cycle. Procedia Soc Behav Sci. 2015;192:638-43.

2. Charness $\mathrm{N}$. The impact of chess research on cognitive science. Psycho Res. 1992;54:4-9.

3. Burgoyne AP, Sala G, Gobet F, Macnamara BN, Campitella G, Hambrick DZ. The relationship between cognitive ability and chess skill: a comprehensive meta-analysis. Intelligence. 2016;59:72-83.

4. Sala G, Gobet F. Do the benefits of chess instruction transfer to academic and cognitive skill?: a meta-analysis. Educ Res Rev. 2016;18:46-57.

5. American Go Association. What is Go? American Go Association. Retrieved from http://www.usgo.org/what-go (January 22, 2019).

6. lizuka A, Suzuki H, Ogawa S, Kobayashi-Cuya KE, Kobayashi M, Fujiwara Y. Pilot randomized controlled trail of the $\mathrm{GO}$ game intervention on cognitive function. Am J Alzheimers Dis Other Dement. 2018;33(3):192-8.

7. Kim SH, Han DH, Lee YS, Kim BN, Cheong JH, Han SH. Baduk (the game of go) improved cognitive function and brain activity in children with attention deficit hyperactivity disorder. Psychiatry Investig. 2014; $11(2): 143-51$.

8. Lin Q, Cao Y, Gao J. The impacts of a GO-game (Chinese chess) intervention on Alzheimer disease in a northeast Chinese population. Front Aging Neurosci. 2015:7:163.

9. Wan X, Takano D, Asamizuya T, Suzuki C, Ueno K, Cheng K, Ito T, Tanaka K. Developing intuition: neural correlates of cognitive-skill learning in caudate nucleus. J Neurosci. 2012;32:17492-501.

10. Amaro S, Viggiano A, Di Costanzo A, Madeo I, Viggiano A, Baccari ME, Marchitelli E, Raia M, Viggiano E, Deepak S, Monda M, De Luca B. Kalèdo, a new educational board-game, gives nutritional rudiments and encourages healthy eating in children: a pilot cluster randomized trial. Eur J Pediatr. 2006;165(9):630-5. 
11. Zeedyk MS, Wallace L, Carcary B, Jones K, Larter K. Children and road safety: increasing knowledge does not improve behavior. Br J Educ Psychol. 2001; 71:573-94.

12. Moher D, Liberati A, Tetzlaff J, Altman DG. Preferred reporting items for systematic reviews and meta-analyses: the PRISMA statement. PLoS Med. 2009;6(7):e1000097.

13. Cohen J. Statistical power analysis for the behavioural sciences. 2nd ed. Lawrence Earlbaum Associates: Hillsdale; 1988.

14. Sala G, Aksayli ND, Tatlidil KS, Gondo Y, Gobet F. Working Memory training does not enhance older adults' cognitive skills: a comprehensive metaanalysis. from file:///C:/Users/noras/AppData/Local/Packages/Microsoft. MicrosoftEdge_8wekyb3d8bbwe/TempState/Downloads/WMT_older_ adults_posting_version\%20(1).pdf (July 22, 2019).

15. Khazaal $Y$, Chatton A, Prezzemolo R, Zebouni F, Edel $Y$, Jacquet J, Ruggeri O, Burnens E, Monney G, Protti AS, Etter JF, Khan R, Cornuz J, Zullino D. Impact of a board-game approach on current smokers: a randomized controlled trial. Subst Abuse Treat Prev Policy. 2013:8:3

16. Wanyama JN, Castelnuovo B, Robertson G, Newell K, Sempa JB, Kambugu A Manabe YC, Colebunders R. A randomized controlled trial to evaluate the effectiveness of a board game on patients' knowledge uptake of HIV and sexually transmitted diseases at the infectious diseases institute, Kampala, Uganda. J Acquir Immune Defic Syndr. 2012;59(3):253-8.

17. Nieh HP, Wu WC. Effects of a collaborative board game on bullying intervention: a group-randomized controlled trial. J Sch Health. 2018;88(10): 725-33.

18. Martins FDP, Leal LP, Linhares FMP, Santos AHDS, Leite GO, Pontes CM. Effect of the board game as educational technology on schoolchildren's knowledge on breastfeeding. Rev Lat Am Enfermagem. 2018;26:e3049.

19. Viggiano E, Viggiano A, Di Costanzo A, Viggiano A, Viggiano A, Andreozzi E, Romano V, Vicidomini C, Di Tuoro D, Gargano G, Incarnato L, Fevola C, Volta P, Tolomeo C, Scianni G, Santangelo C, Battista R, Raia M, Valentino I, Palumbo M, Messina A, Monda M, De Luca B, Amare S. Healthy lifestyle promotion in primary schools through the board game Kaledo: a pilot cluster randomized trial. Eur J Pediatr. 2018:177(9):1371-5.

20. Karbownik MS, Wiktorowska-Owczarek A, Kowalczyk E, Kwarta P, Mokros Ł, Pietras T. Board game versus lecture-based seminar in the teaching of pharmacology of antimicrobial drugs-a randomized controlled trial. FEMS Microbiol Lett. 2016;363(7):fnw045.

21. Viggiano A, Viggiano E, Di Costanzo A, Viggiano A, Andreozzi E, Romano V, Rianna I, Vicidomini C, Gargano G, Incarnato L, Fevola C, Volta P, Tolomeo C, Scianni G, Santangelo C, Battista R, Monda M, Viggiano A, De Luca B, Amaro S. Kaledo, a board game for nutrition education of children and adolescents at school: cluster randomized controlled trial of healthy lifestyle promotion. Eur J Pediatr. 2015;174:217-28.

22. Charlier N, De Fraine B. Game-based learning as a vehicle to teach first aid content: a randomized experiment. J Sch Health. 2013;83:493-9.

23. Bartfay WJ, Bartfay E. Promoting health in schools through a board game. West J Nurs Res. 1994;16(4):438-46.

24. Panphunpho S, Thavichachart N, Kritpet T. Positive effects of Ska game practice on cognitive function among older adults. J Med Assoc Thail. 2013; 96:358-64.

25. Demily C, Cavézian C, Desmurget M, Berquand-Merle M, Chambon V, Franck $\mathrm{N}$. The game of chess enhances cognitive abilities in schizophrenia. Schizophr Res. 2009;107(1):112-3.

26. Sala G, Gorini A, Pravettoni G. Mathematical problem-solving abilities and chess: an experimental study on young pupils. SAGA Open. 2015;5:1-9.

27. Sala G, Gobet F. Does chess instruction improve mathematical problemsolving ability?: two experimental studies with an active control group. Learn Behav. 2017:45:414-21.

28. Aciego R, Garcia $L$, Betancort $M$. The benefits of chess for the intellectual and social-emotional enrichment in schoolchildren. Span J Psychol. 2012;15: 551-9.

29. Aydin M. Examining the impact of chess instruction for the visual impairment on mathematics. Educ Res Rev. 2015;10(7):907-11.

30. Barrett DC, Fish WW. Our move: using chess to improve math achievement for students who receive special education services. Int J Special Educ. 2011 26:181-93.

31. Gliga F, Flesner PI. Cognitive benefits of chess training in novice children. Procedia Soc Behav Sci. 2014;116:962-7.

32. Hong S, Bart WM. Cognitive effects of chess instruction on students at risk for academic failure. Int J Special Educ. 2007;22(3):89-96.
33. Scholz M, Niesch H, Steffen O, Ernst B, Markus L, Witruk E, Schwarz H. Impact of chess training on mathematics performance and concentration ability of children with learning disabilities. Int J Special Educ. 2008;23(3): $138-48$

34. Mouton A, Gillet $N$, Mouton F, Van Kann D, Bruyère $O$, Cloes M, Buckinx F. Effects of a giant exercising board game intervention on ambulatory physical activity among nursing home residents: a preliminary study. Clin Interv Aging. 2017;12:847-58.

35. Fernandes SC, Arriaga P, Esteves F. Providing preoperative information for children undergoing surgery: a randomized study testing different types of educational material to reduce children's preoperative worries. Health Educ Res. 2014;29:1058-76.

36. Blasco-Fontecilla H, Gonzalez-Perez M, Garcia-Lopez R, Poza-Cano B, PerezMoreno MR, de Leon-Ma V, Otero-Perez J. Efficacy of chess training for the treatment of ADHD: a prospective, open label study. Rev Psiquiatr Salud Ment. 2016;9(1):13-21.

37. Barzegar K, Barzegar S. Chess therapy: a new approach to curing panic attack. Asian J Psychiatr. 2017;30:118-9.

38. Wakutani Y, Kusumi M, Wada K, Kawashima M, Ishizaki K, Mori M, Mori N, ljiri T, Adachi Y, Ashida Y, Kuno N, Urakumi K, Takeshima T, Nakashima K. Longitudinal changes in the prevalence of dementia in a Japanese rural area. Psychogeriatrics. 2007:7:150-4.

39. Sala G, Aksayli ND, Tatlidil KS, Tatsumi T, Gondo Y, Gobet F. Near and fear transfer in cognitive training: a second-order meta-analysis. Collabra Psychol. 2019;5:18.

\section{Publisher's Note}

Springer Nature remains neutral with regard to jurisdictional claims in published maps and institutional affiliations.
Ready to submit your research? Choose BMC and benefit from:

- fast, convenient online submission

- thorough peer review by experienced researchers in your field

- rapid publication on acceptance

- support for research data, including large and complex data types

- gold Open Access which fosters wider collaboration and increased citations

- maximum visibility for your research: over $100 \mathrm{M}$ website views per year

At $\mathrm{BMC}$, research is always in progress.

Learn more biomedcentral.com/submissions 